\title{
Primary cutaneous plasmablastic lymphoma revealing clinically unsuspected HIV infection*
}

\author{
Silvio Alencar Marques ${ }^{1}$ \\ Marcelo Massaki Guiotoku²
}

\author{
Luciana P. Fernandes Abbade ${ }^{1}$ \\ Mariangela Esther Alencar Marques ${ }^{1}$
}

DOI: http:/ / dx.doi.org/10.1590/abd1806-4841.20164764

\begin{abstract}
Plasmablastic lymphoma is a rare subtype of diffuse large B-cell lymphoma more frequently diagnosed in immunosuppressed patients, mainly HIV-infected. Primary cutaneous plasmablastic lymphoma is extremely rare, and in this patient it was the first clinical manifestation of unsuspected HIV-infection.
\end{abstract}

Keywords: HIV Infections; Lymphoma, Skin Neoplasms; AIDS-Related

\section{INTRODUCTION}

Plasmablastic lymphoma is a non-Hodgkin lymphoma regarded as a distinct subtype of diffuse large B-cell lymphoma (DL$\mathrm{BCL}){ }^{1}$ It is frequently associated with immunosuppression, mainly human immunodeficiency virus (HIV-induced). Delecleuse HJ et al. (1997) reported 16 clinical cases of aggressive lymphoma, 15 of which were on HIV-infected individuals who displayed the buccal mucosa as the site of primary involvement. ${ }^{2}$ As additional characteristics, the tumors showed plasmacytoid differentiation and positivity to Epstein-Barr virus (EBV) infection in $60 \%$ of the patients. ${ }^{2}$ From the first cases in 1997 until 2008, around 112 HIV-associated cases had been reported, most of which were in male patients $(7: 1)$, average age 38 and $\leq 200$ CD4 T-lymphocytes $/ \mathrm{mm}^{3}$. In 65 of those patients $(58 \%)$, buccal mucosa was the primary site followed by the gastrointestinal tract in 15 patients $(13 \%) .{ }^{3}$ In all cases, at least one plasma-cell marker (CD38, CD138 or MUM1) was positive. Although they were B-cell lymphomas, CD20 was positive in only $3 \%$ of those reported cases. ${ }^{3}$ Primary cutaneous plasmablastic lymphomas are extremely rare with only 12 cases reported by $2014 .^{4,5}$ We present a clinical case of highly aggressive primary cutaneous plasmablastic lymphoma revealing clinically unsuspected HIV infection.

\section{CASE REPORT}

A 60-year-old female patient was admitted for evaluation of a two-year tumoral skin lesion on the leg. She reported occasional fever, weight loss (about 20kg in six months) and eventual clinical worsening. Physical examination revealed a phagedenic and terebrant ulcer with necrotic aspect in the center of the lesion. We observed nodules and tumors in upper limits and an infiltrative and indurate aspect in distal limits (Figures 1 and 2). Oral thrush was also observed. Based on clinical observations, we suspected non-Hodgkin lymphoma or fibrosarcoma. Histopathology examination revealed the same pattern in all sections: dense monomorphic atypical lymphocytic infiltration of superficial and deep dermis. Lymphocytes showed plasmacytoid differentiation with abundant eosinophilic cytoplasm, eccentric nucleus and prominent nucleolus (Figures 3 and 4). Lesions demonstrated multiple mitosis. Immunostaining was positive for CD38 and CD138 and negative for CD3, CD20 and CD45 (Figure 5). KI-67 proliferative index was highly positive $(80 \%)$. Image analysis and bone marrow biopsy revealed no systemic involvement caused by the lymphoma. In situ hybridization identified EBV genome within tumor cells and EBV serology was positive for IgG and negative for IgM. Serological investigation

Received on 28.05.2015

Approved by the Advisory Board and accepted for publication on 07.07.2015

Work performed at Departament of Dermatology and Radiotherapy - School of Medicine - Universidade Estadual Paulista "Júlio de Mesquita Filho" (UNESP)

- Botucatu (SP), Brazil.

Financial Support: None.

Conflict of Interest: None.

Universidade Estadual Paulista “Júlio de Mesquita Filho" (UNESP) - Botucatu (SP), Brazil.

Clinica Particular - São Paulo (SP), Brazil.

(C)2016 by Anais Brasileiros de Dermatologia 


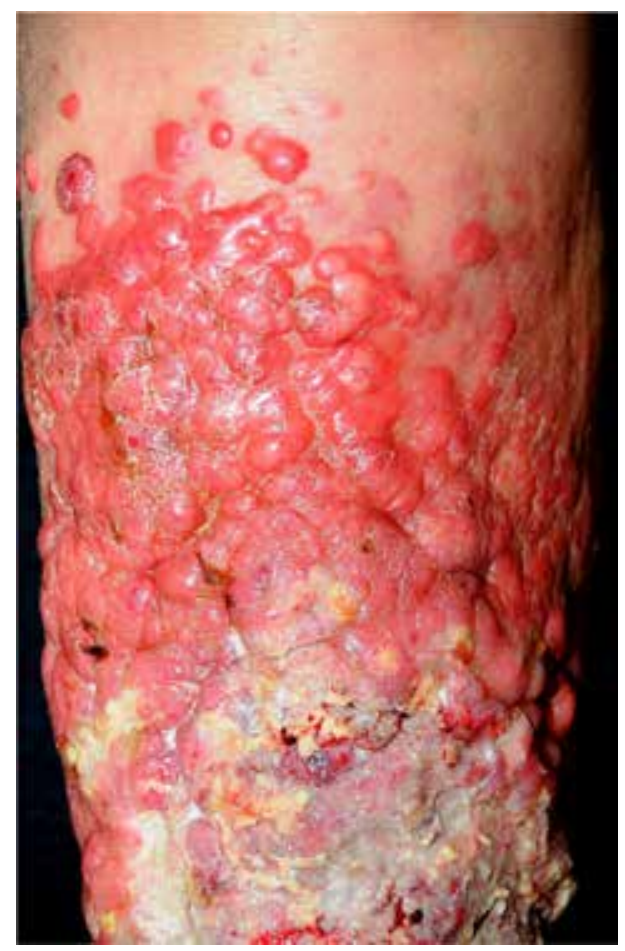

Figure 1:

Plasmablastic lymphoma: a phagedenic and terebrant ulce with nodules and tumors on its upper limits

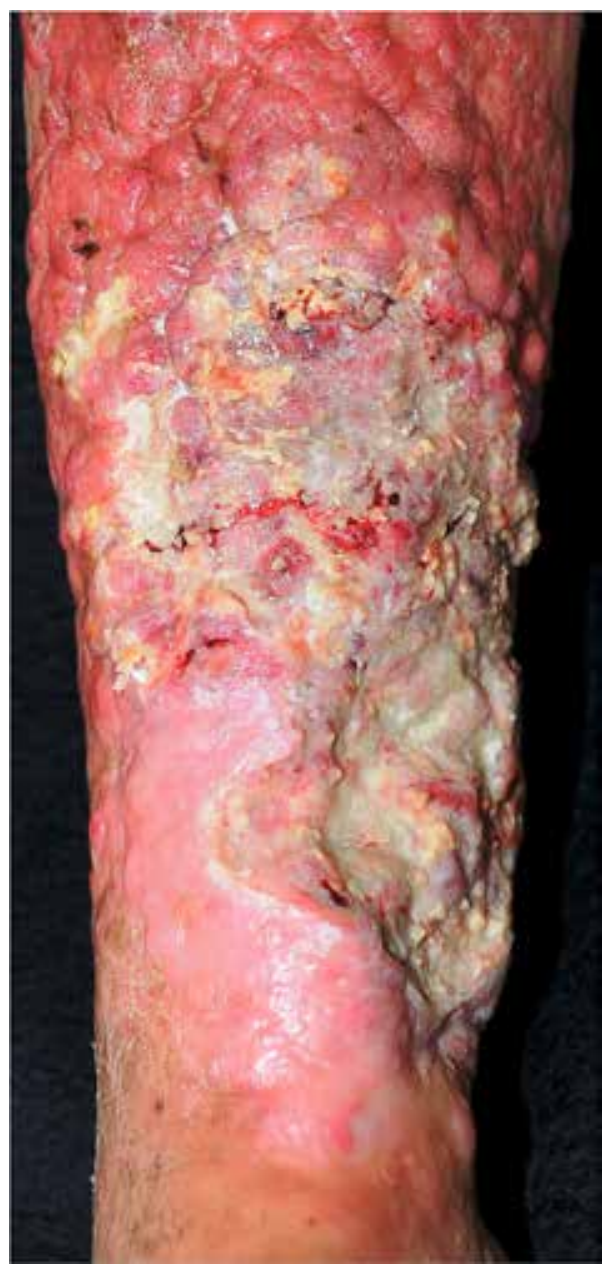

Figure 2:

Plasmablastic lymphoma: distal limits showing infiltrative and indurate aspect

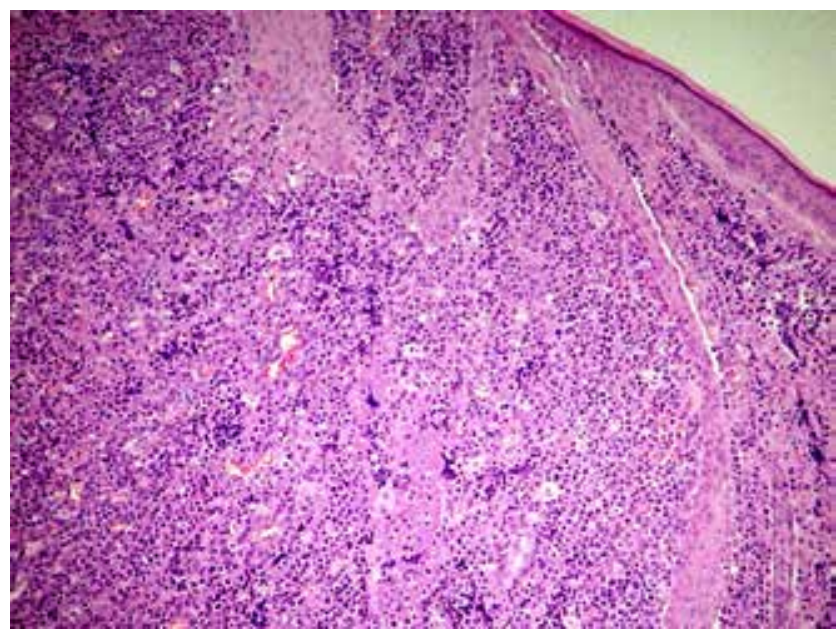

Figure 3: Plasmablastic lymphoma: dense monomorphic atypical lymphocytic infiltration of superficial and deep dermis. Epidermis is preserved. HE $100 \mathrm{X}$

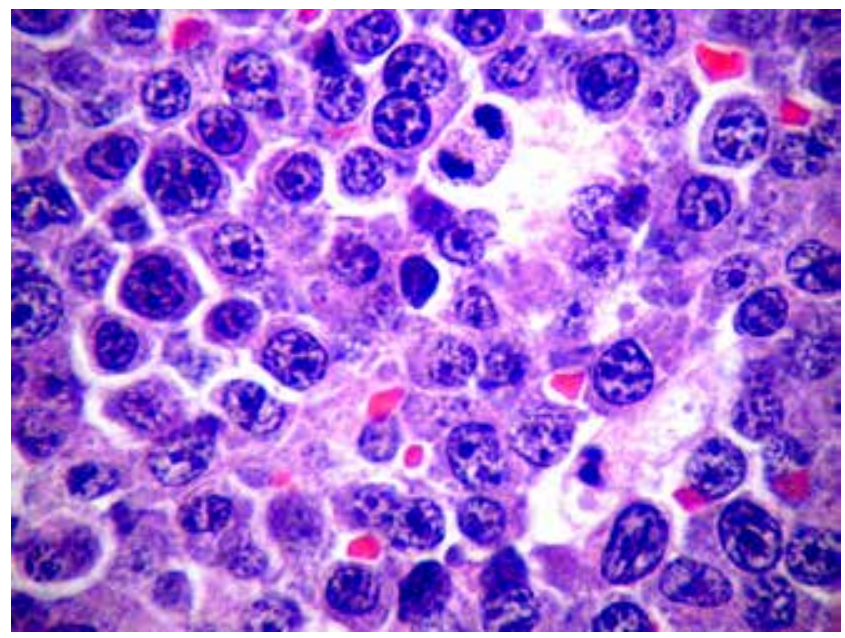

Figure 4: Plasmablastic lymphoma: cells with a plasmacytoid appearence with a clock-face condensation of the chromatin. HE 1000X

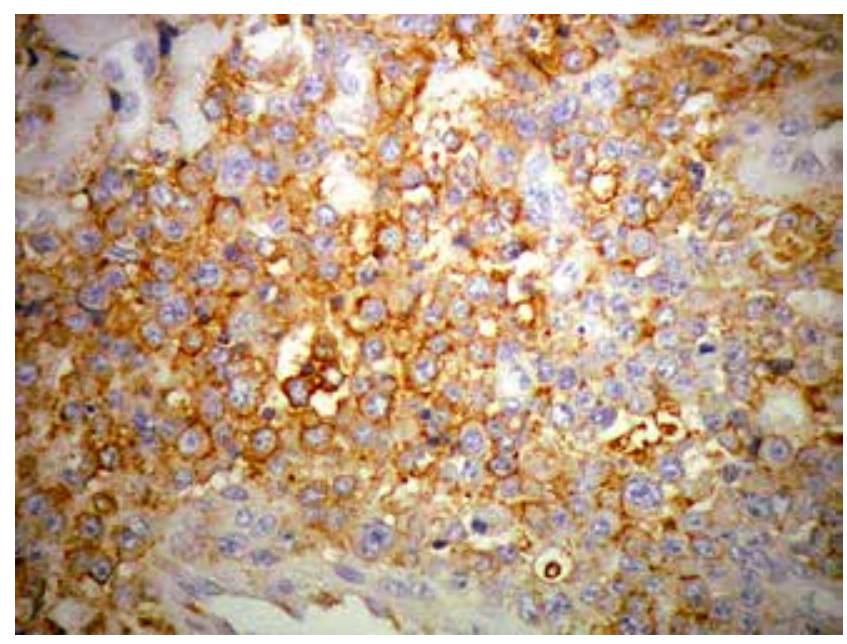

Figure 5: Plasmablastic lymphoma: neoplastic cells staining for CD138. IMQ 400X 
for HIV-infection was positive and presented CD4 T-lymphocytes 93 cells $/ \mathrm{mm} 3$, CD8 T-lymphocytes $=1403 / \mathrm{mm} 3$ and viral load of 80.000 copies/ml. Human herpesvirus-8 (HHV-8) investigation by PCR was negative. Additional clinical or laboratory analysis were unremarkable. The final diagnosis was primary cutaneous plasmablastic lymphoma associated with HIV-infection. Differential histopathological diagnoses considered in this case were plasma cell neoplasm with a plasmablastic morphology, another HIV-related aggressive diffuse large B-cell lymphoma and primary cutaneous B-cell lymphoma, leg-type.

CHOP (cyclophosphamide, hydroxydaunorubicin, oncovin and prednisone) chemotherapy regimen was associated with antiretroviral treatment (HAART). Nevertheless, the patient could stand only one cycle of standard CHOP chemotherapy and died 21 days after the diagnosis.

\section{DISCUSSION}

Non-Hodgkin lymphoma, Kaposi sarcoma and invasive carcinoma of the uterine cervix are the only tumors included in the HIV surveillance data. ${ }^{6}$ Non-Hodgkin lymphomas (NHL) are much more frequent among HIV-infected individuals than the general population. $90 \%$ of those NHL are B-cell lymphomas, most of which are extranodal such as the primary central nervous system lymphoma, Burkitt's lymphoma and diffuse large B-cell lymphomas. ${ }^{7}$ Plasmablastic lymphoma is a subtype of DLBCL with specific characteristics: a typical extranodal lymphoma associated with immunosuppression, mostly HIV-induced and mostly seen in the buccal mucosa. It occurs less often in transplanted patients and rarely in non-immunosuppressed individuals. Histopathology usually shows a dense infiltrate of immunoblast-like or plasmablast-like cells with strong positivity to CD38, CD138, MUM1 and negativity for T-cell markers. In general, only $2 \%-3 \%$ of the cells are positive for CD20. KI-67 immunostaining reveals $50 \%-100 \%$ positivity. ${ }^{8}$ In situ hybridization identifies EBV genome within tumor cells in up to $75 \%$ of the cases when using EBV-encoded small RNA (EBER) probes or antibody staining for latent membrane protein. ${ }^{8}$ Its pathogenic role would be to provide protection against apoptosis of lymphocyte B through amplification of MYC oncogene expression in a similar mechanism observed in Burkitt's lymphoma. ${ }^{9}$ The detection of concomitant HHV-8 infection occurs in less than $50 \%$ of the cases and its etiopathogenic role in developing the plasmablastic lymphoma is not well defined. ${ }^{8}$

The clinical presentation of buccal plasmablastic lymphoma is of a rapidly growing tumoral and painful mass, mostly located on gingiva, followed by lesions on palate and the floor of the mouth, which may infiltrate the adjacent bone. ${ }^{10}$

Although primary cutaneous plasmablastic lymphoma is extremely rare, it seems to share a common pattern, namely the incidence of an ulcerative or infiltrative lesion on the legs. ${ }^{5}$ Its diagnosis implies the investigation of subjacent immunosuppression, particularly HIV-induced. However, it can also be observed in patients in immunosenescence state when the term plasmablastic lymphoma of the elderly (PBL-E) is used. ${ }^{4}$

Treatment has not been standardized. Case-by-case decisions have been proposed with the use of CHOP chemotherapy regimen, radiation therapy, surgical excision or combination of these methods. The addition of HAART is the rule in case of HIV-related plasmablastic lymphoma. ${ }^{8}$

\section{REFERENCES}

1. Stein H, Harris NL, Campo E. Plasmablastic lymphoma. In: Swerdlow SH, Campo E, Harris NL, Jaffe ES, Pileri SA, et al, editors. World Health Organization classification of tumors of hematopoietic and lymphoid tissues. 4th ed. IARC Press Lyon; 2008. p.256-257.

2. Delecluse HJ, Anagnostopoulos I, Dallenbach F, Hummel M, Marafioti T, Schneider $\mathrm{U}$, et al. Plasmablastic lymphomas of the oral cavity: A new entity associated with the human immunodeficiency virus infection. Blood. 1997;89:1413-20.

3. Castillo J, Pantanowitz L, Dezube BJ. HIV-associated plasmablastic lymphoma: Lessons learned from 112 published cases. Am J Hematol. 2008;83:804-9.

4. Tiong IS, Strauss M, Lau MB, Chiruka S. Cutaneous plasmablastic lymphoma in an immunocompetent patient with long-term pyrimethamine Use for essential chrombocythemia: A Case report and literature review. Case Rep Hematol. 2013;2013:541783.

5. Tavares MD, Magalhães TC, de Moraes FM, Piñeiro-Maceira J, Ramos-e-Silva M. Plasmablastic lymphoma: a rare and exuberant cutaneous emergence in an immunocompetent patient. Int J Dermatol. 2015;54:e175-8.

6. Cheung MC, Pantanowitz L, Dezube BJ. AIDS-related malignancies: emerging challenges in the era of highly active antiretroviral therapy. Oncologist. 2005; $10: 412-26$

7. Corti M, Carolis LD, Solari R, Villafañe MF, Schtirbu R, Lewi D, et al . NonHodgkin's lymphoma with cutaneous involvement in AIDS patients. Report of five cases and review of the literature. Braz J Infect Dis. 2010;14:81-5.
8. Castillo JJ, Reagan JL. Plasmablastic Lymphoma: A Systematic review. ScientificWorldJournal. 2011;11:687-96.

9. Valera A, Balagué 0, Colomo L, Martínez A, Delabie J, Taddesse-Heath L. IG/MYC rearrangements are the main cytogenetic alteration in plasmablastic lymphomas. Am J Surg Pathol. 2010;34:1686-94.

10. Sarode SC, Sarode GS, Patil A. Plasmablastic lymphoma of the oral cavity: A review. Oral Oncol. 2010;46:146-53.

MAILING ADDRESS:

Silvio Alencar Marques

Departamento de Dermatologia e Radioterapia da Faculdade de Medicina de Botucatu - UNESP

Distrito de Rubião Junior $S / N$

18618-970 - Botucatu - SP

Brazil

E-mail:smarques@fmb.unesp.br

How to cite this article: Marques SA, Abbade LPF, Guiotoku MM, Marques MEA. Primary cutaneous plasmablastic lymphoma disclosing an unknown HIV-infection. An Bras Dermatol. 2016;91(4):507-9. 